\title{
ALGUNAS CONSIDERACIONES SOBRE LA PROTECCIÓN DE DATOS EN EL TRATAMIENTO DE MUESTRAS BIOLÓGICAS Y DATOS DE SALUD CON FINALIDAD DE CONTROL ANTIDOPAJE EN EL ÁMBITO DEPORTIVO: EL PASAPORTE BIOLÓGICO ${ }^{1}$
}

\author{
Dra. Elena Atienza Macías \\ Doctora en Derecho por la Universidad de Deusto. Investigadora Postdoctoral del Gobierno \\ Vasco en laUniversidad del País Vasco UPV/EHU. Facultad de Derecho - Grupo de \\ Investigación Cátedra de Derecho y Genoma Humano.
}

RESUMEN: Este trabajo reflexiona sobre las implicaciones jurídicas del tratamiento de muestras biológicas y datos personales con finalidad de control antidopaje en el ámbito deportivo. A largo de los últimos años, el control del dopaje en las competiciones deportivas se ha convertido en una preocupación de primer orden con una importante proyección y alcance social, habida cuenta el impacto que el dopaje produce en la salud de los deportistas, en la igualdad de condiciones de los participantes de distintas competiciones y finalmente, como factor de "perversión" de los valores que se intentan transmitir a partir de las prácticas deportivas a la sociedad en su conjunto. Esto ha llevado a que diferentes instituciones públicas y privadas desarrollen mecanismos para evitar esta práctica. La lucha contra las prácticas dopantes se ha constituido en la prioridad de estas acciones y nos resulta muy oportuno plantearnos, si este panorama normativo, los procedimientos que se han establecido y la práctica de los controles, es respetuoso y contempla el marco más general referido a la protección de derechos fundamentales, recogidos, tanto en las normas fundamentales de los diferentes países, como en la Carta Europea de Derechos.

ABSTRACT: This paper reflects on the legal implications of the treatment of biological samples and personal data with the purpose of anti doping control in the sports field. The impact that doping has on the athletes` health, on the participants` equal conditions and finally as a factor of "perversion" of the values or ethics in sport (attempting to convey bad sports practices to society as a whole) - three pillars underlying the anti-doping regimehas led private and public -national and international- bodies to develop mechanisms for forbidding this practice. As a result of all this, the control of doping in sport competitions has become a major concern having acquired a high social dimension during the last years. In parallel, this concern has mirrored in the policy-making sphere. The fight against doping practices has become a priority of these actions and it is very opportune to consider, if this regulatory framework that have been established and the practice of controls, is respectful and contemplates the more general framework referred to the protection of fundamental

\footnotetext{
${ }^{1}$ El presente trabajo de investigación se enmarca dentro del Programa Postdoctoral del Gobierno Vasco, de Perfeccionamiento de Personal Investigador Doctor al que la autora está adscrita. Igualmente, se ha contado con el apoyo del Proyecto de Investigación "BIGDATIUS: Uso de datos clínicos ante nuevos escenarios tecnológicos y científicos —Big Data-. Oportunidades e implicaciones jurídicas" — UPV/EHU. Ref.: DER2015-68212-R (MINECO/FEDER) y con la ayuda (con Ref. No IT1066-16) concedida por el Departamento de Educación del Gobierno Vasco para apoyar las actividades de Grupos de Investigación del Sistema Universitario Vasco.
} 
rights, both in the fundamental norms of the different countries and in the European Charter of Rights.

PALABRAS CLAVE: Dopaje / Muestras biológicas / Datos de salud / Protección de datos / Pasaporte Biológico / Derecho a la intimidad.

KEYWORDS: Doping / Biological samples / Health data / Data protection / Biological Passport / Right to privacy.

\section{Introducción}

El archiconocido "Caso Armstrong" marcaría un antes y un después en la actitud que los agentes deportivos han adoptado, a nivel internacional, frente al dopaje. En lo que a este trabajo especialmente atañe, la sonada confesión del ciclista en la que declaraba haber recurrido al dopaje, de manera sistemática, ponía, sin atisbo de duda, en tela de juicio la eficacia del tradicional sistema de control del dopaje en la medida en que los innumerables análisis efectuados al célebre ciclista fueron incapaces de detectar el uso y consumo de sustancias y métodos prohibidos en el deporte, de los que el propio Armstrong reconoció haberse valido, para obtener la victoria en siete ocasiones del conocido Tour de Francia ${ }^{2}$.

Este popular caso - unido a otros no menos importantes e influyentes en la opinión pública como, a nivel nacional, el de la atleta Marta Domínguez acusada por la Federación Internacional de Atletismo (International Association of Athletics Federations o IAAF) y por la Agencia Mundial Antidopaje (AMA) de anormalidades en el Pasaporte Biológico ponía, sin duda, en evidencia la eficacia de los controles antidopaje.

\section{El llamado "Pasaporte Biológico"}

\subsection{Razón de ser del mecanismo conocido como "Pasaporte Biológico"}

La crisis del sistema del control descrita en líneas anteriores, ha empujado a que los tradicionales métodos fundados en el análisis de las muestras fisiológicas de los deportistas -fundamentalmente orina y sangre con el fin de detectar la presencia de sustancias o métodos prohibidos-, hayan tenido que ser complementados con los métodos de detección indirecta del uso de esas sustancias o métodos. El sistema denominadoAthleteBiological Passport (ABP), traducido como "Pasaporte Biológico" (o PB) del deportista constituye la herramienta más reciente y sofisticada en lo que a detección de dopaje indirecta ${ }^{4}$ se refiere. Insistimos en este punto en que la introducción de este mecanismo no supone, en modo alguno, la supresión de los controles "ordinarios" (es decir, los que buscan la detección de

\footnotetext{
${ }^{2}$ HARdiE, Martin, "Lance Armstrong”,Drugs and Sport, Møller,Verner /WADDINGTON, Ivan / HoBERMAN, John M. (Eds.), Ed. Routledge, Nueva York, 2015, pp. 203-204.

${ }^{3}$ En la doctrina, se ha ocupado de este tema, entre otros, Álvarez VIEJO, Julia Amada, "El caso de Marta Domínguez: el pasaporte biológico", Revista Aranzadi de Derecho de Deporte y Entretenimiento, Núm. 42, 2014, pp. 247-288.

${ }^{4}$ Ver, entre otros,MaVRomatia, Despina, "Indirect detection methods for doping from a legal perspective: the case of the Athlete Biological Passport", International Journal of Sport Policy and Politics, Núm. 2, Vol. 6, 2014, pp. 241-258 y VERNEC,Alan R., "TheAthleteBiological Passport: an integral element of innovativestrategies in antidoping", British Journal of Sports Medicine, Núm. 10, Vol. 48, 2014, pp. 817-819.
} 
sustancias dopantes en el cuerpo de los deportistas) sino que se trata de herramientas de control complementaria o, en términos que señala la propia doctrina especializada ${ }^{5}$, "estrategia complementaria".

Hemos de hacer notar que si bien la noticia sobre el caso de dopaje sistemático del ciclista salía a luz en 2013, un año antes, concretamente a inicios del mes de marzo de 2012, el Parlamento francés aprobaba una proposición de ley por la cual se instauraba la figura del Pasaporte Biológico en todos los deportes para julio de 2013, afectando a todos los deportistas de alto nivel, ya fuesen profesionales o de categorías inferiores, previendo sanciones que pueden llegar a la suspensión perpetua ${ }^{6}$. Previamente a esa fecha este instrumento ya había sido instaurado por otros organismos deportivos ${ }^{7}$. El primero en instaurarlo fue la UnionCyclisteInternationaleo $\mathrm{UCI}^{8}$ - como no podía ser de otra forma por la controversia que han venido generando los innumerables casos de dopaje en el contexto del ciclismo-que en enero de 2008 comenzaba su implantación ${ }^{9}$. A esta iniciativa le siguió la UKAD (UK Anti-Doping o Agencia Antidopaje del Reino Unido), la cual aprobó el uso del Pasaporte Biológico en febrero de 2010; la IAAF (Federación Internacional de Atletismo), que introdujo el mencionado pasaporte por primera vez en los Mundiales de Daegu de 2011, practicando los análisis correspondientes a dicho pasaporte a todos los atletas que tomaron parte en dicha competición (cerca de 2.000) y, finalmente, la FINA (Federación Internacional de Natación), que hizo lo propio en los Mundiales de Shanghái de 2011, habiendo aprobado dicha figura el 31 de julio de 2011.

Finalmente, destacar que sería en el seno de los Juegos Olímpicos de Londres de $2012^{10}$, cuando el Pasaporte Biológico sería implantado por primera vez ${ }^{11}$ en unos Juegos Olímpicos de verano, tras haber sido acordado por el Comité Olímpico Internacional (COI). Sin

\footnotetext{
${ }^{5}$ ZORZOLI, Mario, "Biological passport parameters", Journal of Human Sport and Exercise, Núm. Extra 1, Vol. 6, 2011, pp. 205-217.

${ }^{6}$ En efecto, en Francia el pasaporte biológico resulta obligatorio para todos los deportistas de alto nivel. V. AEPSAD, "¿Qué es el Pasaporte Biológico?", Dopaje: lo que debes saber, 6 de noviembre de 2014, disponible en: http://blog.aepsad.es/que-es-el-pasaporte-biologico/ [Última consulta: 30 de octubre de 2017].

${ }^{7}$ En cuanto al origen, se señala que el uso de marcadores biológicos comenzó a principios de los años ochenta, para detectar la presencia de esteroides anabolizantes en la orina de los atletas. En 1997, la UCI y la Federación Internacional de Esquí introdujeron marcadores sanguíneos para determinar el abuso de EPO, que era indetectable por medios directos en ese tiempo. A partir de 2002 se empieza a utilizar el término "pasaporte biológico" y en 2008 fue aprobado definitivamente. AEPSAD, “¿Qué es el Pasaporte Biológico?”, Dopaje: lo que debes saber, 6 de noviembre de 2014, disponible en: http://blog.aepsad.es/que-es-el-pasaporte-biologico/ [Última consulta: 30 de octubre de 2017].

${ }^{8}$ Para un panorama general del pasaporte biológico, v. UCI,TheAthleteBiological Passport - ABP, 24 de julio de 2014, disponible en: http://www.uci.ch/clean-sport/the-athlete-biological-passport-abp/ [Última consulta: 30 de octubre de 2017].

${ }^{9}$ Cfr. PAtRicK, Kirsten, "Passport to clean competition", British Medical Journal, Núm. 7858, Vol. 344, 2012, p. 20 y HAILEY, Nicholas, "A false start in the race against doping in sport: concerns with cycling's biological passport", Duke Law Journal, Núm. 2, Vol. 61, 2011, pp. 393-397.

${ }^{10}$ HUNTER, Mark, "Would-be cheats face barrage of tests by army of antidoping scientists at London Olympics", British Medical Journal, Núm. 7823, Vol. 343, 2011, p. 553.

${ }^{11}$ El fondista portugués Hélder Ornelas, suspendido cuatro años por la Federación Portuguesa, se convertiría en el primer atleta sancionado por una infracción de dopaje sobre la base de los datos proporcionados por su pasaporte biológico.V. TeIXEIRA SILVEIRA, Viviane / RIGO, Luiz Carlos, "O programa passaporte biológico: considerações sobre o governo dos atletas", Movimento, Núm. 2, Vol. 21, Abril-Junio 2015, pp. 500-501.
} 
embargo, el Pasaporte Biológico solo se podía utilizar en aquellos deportes cuyas federaciones internacionales tienen ya implantado dicho sistema de control, tal es el caso del atletismo, ciclismo, triatlón, pentatlón moderno, remo o natación ${ }^{12}$.

\subsection{Conceptualización y tipología}

De forma muy ilustrativa se optó por denominar a este instrumento de control indirecto del dopaje como Pasaporte Biológico, el cual, de hecho, presenta ciertas similitudes con el pasaporte común que utiliza todo ciudadano de a pie para viajar de un país a otro, es decir, con el fin de identificación ante las autoridades de otros países ${ }^{13}$. En cambio, este documento, específico en sede deportiva, no sólo identifica a los deportistas, sino que pretende actuar como prueba fehaciente del juego limpio de todos ellos, en la medida en que él se recogen todos los resultados de los análisis realizados a cada atleta y con ello, los especialistas pueden establecer un perfil hematológico y urinario del deportista para detectar posibles cambios producidos por la utilización de sustancias dopantes.

Más específicamente, puede definirse en base a una serie de particularidades, como son las que se refieren a que se trata de un documento individual perteneciente a cada deportista que recoge los resultados correspondientes a los análisis realizados a cada atleta, más factores heterogéneos únicos de cada uno. Este instrumento crea tres perfiles diferentes derivados de los resultados de los controles sanguíneo y urinario (hematológico, esteroideo y endocrinológico), perfiles que representan los parámetros del organismo de un deportista en concreto y tiene por finalidad la comparativa de los perfiles con las muestras posteriores y de esta forma, contemplar posibles variaciones anómalas ${ }^{14}$. Mediante dichos perfiles, se realiza un seguimiento de la evolución de los parámetros de cada deportista, facilitando la detección de variaciones anormales, que puedan ser consecuencia de prácticas dopantes, además de otras posibles causas. En otros términos, el propósito del Pasaporte Biológico es el de controlar unos biomarcadores o parámetros biológicos del deportista ${ }^{15}$, de forma prolongada en el tiempo, de tal manera que, en el supuesto de apreciarse variación respecto al perfil

\footnotetext{
${ }^{12}$ Cfr. ZORZOLI, Mario / PIPE, Andrew Lawrence / GARNIER, Pierre-Yves / DvORAK, Jiri, "Practical experience with the implementation of an athlete's biological profile in athletics, cycling, football and swimming", British Journal of Sports Medicine, Núm. 10, Vol. 48, 2014, pp. 862-866.

${ }^{13}$ Matiza GILBERT que al igual que un pasaporte al uso se requiere para la entrada en países extranjeros, el pasaporte biológicose requiere ahora a muchos atletas para su incursión en las competiciones de élite. En palabras de la autora "Like a valid passport required for entry into foreign countries, a valid (clean) biological passport is now required for many athletes to gain entry into elite competitions". Cfr. GILBERT, Susan, "The Biological Passport", Hastings Center Report, Núm. 2, Vol. 40, 2010, pp. 18-19.

${ }^{14}$ AMILIBIA PÉREZ, Guillermo, "El pasaporte biológico: luces y sombras. ¿Todo vale?”, Iusport, 9 de abril de 2012, disponible en: http://www.iusport.es/images/stories/autores/Guillermo-Amilibia-pasaporte-biologico2012.pdf[Última consulta: 30 de octubre de 2017].

${ }^{15}$ Mario Zorzoli, en su función de Consejero Científico de la UCI ha plasmado su experiencia en cuanto al desarrollo e implementación del pasaporte biológico en trabajos de investigación tales como: ZoRZOLI, Mario, "Biological passport parameters", Journal of Human Sport and Exercise, Núm.Extra 1, Vol. 6, 2011, pp. 205217 y del mismo "The Athlete Biological Passport from the perspective of an anti-doping organization", Clinical Chemistry and Laboratory Medicine, Núm. 9, Vol. 49, 2011, pp. 1423-1425. Cfr. Asimismo ZorZOLI, Mario / RossI, Francesca, "Implementation of the biological passport: the experience of the International Cycling Union”, Drug Testing and Analysis, Special Issue: 28th Cologne Workshop: Advances in Sports Drug Testing, Núms. 11-12, Vol. 2, 2010, pp. 542-547.
} 
creado con anterioridad, implique un indicio de dopaje en el comportamiento del deportista en cuestión.

La gran diferencia con respecto al tradicional sistema de control estriba en que, en este caso, no se buscan sustancias prohibidas en el cuerpo del deportista, es decir, "positivos", sino fluctuaciones en sus constantes que indirectamente puedan revelar, entre otras causas, el haber llevado a cabo conductas tipificadas como violación de las normas antidopaje. De tal manera que no se requiere demostrar por medio de un resultado analítico adverso que una sustancia prohibida ha entrado en el organismo de un deportista, sino que es suficiente con hallar una variación en sus perfiles para poder iniciar un procedimiento disciplinario. Frente a ello, con el sistema de detección directa, es decir, sustancias prohibidas en el cuerpo de los deportistas, resulta ciertamente complicado encontrar sustancias que hayan sido utilizadas de manera intermitente y en pequeñas dosis, habida cuenta el cuerpo las elimina de forma rápida y los tests son llevados a cabo en un único momento en el tiempo. Por contra, los efectos de dichas sustancias en los parámetros biológicos del deportista duran mucho más tiempo que las propias sustancias en su cuerpo. Si bien ha de hacerse notar que una variación no tiene como causa única la práctica de dopaje, sino que puede ser fruto de una concatenación de causas, pongamos por caso, el estar sometido a un tratamiento médico concreto o haber sufrido una enfermedad que hubiera afectado a los niveles biológicos del deportista, entre otras razones. Este último aspecto será tratado en el apartado crítico.

En puridad, el propósito cardinal que se persigue con esta herramienta es la disuasión del consumo de sustancias prohibidas o del empleo de métodos prohibidos por parte de los deportistas, habida cuenta de que, con la mera variación de sus parámetros, incluso sin llegar a detectar ninguna sustancia prohibida, el deportista puede resultar sancionado de forma severa. Podemos hablar, por ende, de un claro instrumento de prevención con un manifiesto efecto disuasivo ${ }^{16}$.

En lo concerniente a la tipología, se han desarrollado, hasta el momento, dos pasaportes biológicos que se refieren a los perfiles hematológico, es decir, detectado en la sangre de los deportistas y el perfil esteroideo que se refiere a la detección en pruebas de orina a los atletas. Como tercera modalidad se prevé el perfil endocrinológico que, no obstante, hasta la fecha no se ha puesto en ejercicio, estando todavía en fase de desarrollo.

Es el pasaporte basado en datos hematológicos el que ha sido más desarrollado hasta el momento, basado en el seguimiento a lo largo del tiempo de variables hematológicas seleccionadas que pueden revelar, indirectamente, los efectos del dopaje (por oposición a la detección directa del dopaje a través de métodos analíticos). Se trata de la suma de los controles sanguíneos efectuados a un deportista, estableciendo sus límites individuales en

\footnotetext{
${ }^{16}$ Sobre este efecto disuasivo (o "deterrence effect") se pronuncia VIRET, Marjolaine, "Athlete Biological Passport: a paradigm shift?", Evidence in anti-doping at the intersection of Science \& Law, Springer ASSER International Sports Law Series, Berlín, 2015, p. 728 y GLEAVES, John, "What to do once they're caught", Cycling - Philosophy for Everyone: A Philosophical Tour de Force, ILundáIn-AgurruZA, Jesús / Austin, Michael W. (Eds.), Wiley-Blackwell, Malden, 2010, p. 191. Sobre el impacto de la introducción de este instrument cfr. VERNEC, Alan R., "The Athlete Biological Passport: an integral element of innovative strategies in antidoping”, op. cit., p. 2.
} 
pro de comparar dicho perfil con las futuras muestras. Este tipo de pasaporte hematológico ${ }^{17}$ tendría como objetivo, según lo que previamente hemos comentado, la identificación de los deportistas sospechosos a los que irán dirigidos los controles antidopaje y, por otra parte, constituye una prueba de dopaje por infracción consistente en el uso de sustancias o métodos prohibidos.

De otro lado, el perfil esteroideo ${ }^{18}$ es un perfil creado en base a los resultados analíticos obtenidos de muestras de orina del deportista y el endocrinológico se basa en los datos derivados de la segregación hormonal del sistema endocrino. Estos dos últimos perfiles no han sido desarrollados efectivamente para la gran mayoría de deportes, siendo la UCI la primera institución que empezó a desarrollar el Pasaporte Biológico tanto a nivel hematológico como esteroideo, siendo el ciclismo el deporte que hasta ahora ha conseguido implantar los dos perfiles en cuestión.

Ciertamente, el objetivo último es aunar los tres módulos en pro de la obtención de un perfil único y total del deportista y, de esta forma, ampliar sustancialmente el poder del Pasaporte Biológico y el número de modalidades deportivas ${ }^{19}$ en la que adquiera virtualidad.

\subsection{Régimen normativo nacional e internacional}

A nivel nacional, la LO 3/2013 si bien ha contemplado, efectivamente, por primera vez, la posibilidad de emplear el Pasaporte Biológico como medio de prueba, no define esta figura ni regula su puesta en marcha y funcionamiento por las autoridades españolas. Se contempla este instrumento en el artículo 1.3 de dicha Ley estableciendo que los deportistas calificados oficialmente como de nivel internacional o que participen en competiciones de este rango están sometidos a las normas y procedimientos de la Federación internacional correspondiente y de la AMA, incluyendo los referentes al Pasaporte Biológico, si existiesen; por su parte el artículo 39.4 señala que en el seno del procedimiento sancionador en materia de dopaje la Administración y la persona afectada por aquél podrán servirse de todos los medios de prueba admisibles en derecho, incluido el Pasaporte Biológico si existiesen datos sobre el mismo. Dichas pruebas deberán valorarse de modo conjunto de acuerdo con las reglas de la sana crítica.

A nivel internacional, uno de los puntos clave del Código Mundial Antidopaje o CMA de $2015^{20}$ se centra, precisamente, en este aspecto. La implementación del nuevo Código con el

\footnotetext{
${ }^{17}$ RODRÍGUEZ GARCÍA, José, "El pasaporte hematológico como nuevo elemento de prueba en la lucha contra el dopaje”, Dopaje deportivo y Código Mundial Antidopaje, DE VICENTE MARTínEZ, Rosario (Dir.), MiLlÁN GARRIDO, Antonio (Coord.), Ed. Reus, Madrid, 2014, pp. 106.

${ }^{18}$ La Cuarta versión de las Directrices sobre pasaporte biológico (Athlete Biological Passport Guidelines) que fueron aprobadas por el Comité Ejecutivo de la AMA en noviembre de 2013, introdujo este segundo módulo, el esteroideo, que entró en funcionamiento el 1 de enero de 2014. V. AMA, "Athlete biological passport", Science \& Medical, disponible en: https://www.wada-ama.org/en/what-we-do/science-medical/athlete-biologicalpassport [última consulta: 30 de octubre de 2017].

${ }^{19}$ Cfr. ZORZOLI, Mario / PIPE, Andrew Lawrence / GARNIER, Pierre-Yves / DvORAK, Jiri, "Practical experience with the implementation of an athlete's biological profile in athletics, cycling, football and swimming", British Journal of Sports Medicine, Núm. 10, Vol. 48, 2014, pp.862-866.

${ }^{20} \mathrm{Cfr}$. DvORAK, Jiriet ál., "Time for change: a roadmap to guide the implementation of the World Anti-Doping Code 2015”, British Journal of Sports Medicine, Núm. 10, Vol. 48, 2014, pp. 801-806.
} 
énfasis en unas pruebas más inteligentes ofrece una gran oportunidad para la mejora de esta herramienta, de modo que resulte más eficaz y eficiente para el control de dopaje. El Pasaporte Biológico del atleta representa una nueva oportunidad para asegurar una prueba más estratégica. En este sentido, el uso del Pasaporte Biológico como medio de prueba deriva de la aplicación del artículo 3.2 CMA al establecer que los hechos relativos a infracciones de las normas antidopaje pueden probarse por cualquier medio fiable, incluidas las confesiones. En el comentario que el propio Código realiza a ese precepto dice que una organización antidopaje puede determinar la existencia de una infracción de las normas antidopaje según el artículo 2.2 (uso o intento de uso de una sustancia prohibida o de un método prohibido) a partir de las conclusiones extraídas del perfil de una serie de muestras de sangre o de orina del deportista, como los datos procedentes del Pasaporte Biológico del deportista. Es importante hacer notar que, como complemento al Código, la AMA viene publicando unas directrices sobre el funcionamiento del Pasaporte Biológico (Athlete Biological Passport Guidelines), con el fin de promover la armonización de los programas de Pasaporte Biológico, facilitar el intercambio de la información y el reconocimiento mutuo de los datos y, en consecuencia, para mejorar su eficiencia. Al igual que sucede con todas las directrices previstas en el Código, este documento está sujeto a una revisión y evaluación continua para asegurarse de que sigue reflejando las mejores prácticas ${ }^{21}$.

\subsection{Valoraciones críticas}

La figura del Pasaporte Biológico viene siendo objeto de acalorados debates desde que la AMA sugirió la idea de su promoción e implantación, allá por 2002. Y es que por lo que a la lucha contra el dopaje atañe, la ponderación de intereses y bienes jurídicos es imprescindible e impostergablepara la correcta y equitativa aplicación de un sistema como el descrito. Y más teniendo en cuenta que desde algún sector de la doctrina ${ }^{22}$ se afirma que "desde Suiza (desde los altos ejecutivos antidopaje) se defiende el todo vale". De hecho una de las críticas vertidas contra este instrumentos, apuntan a que el Pasaporte Biológico está avalado por el concepto amplísimo dado por el CMA a los medios disponibles para acreditar el uso de sustancias y métodos prohibidos de tal manera que parece que cualquier medio es válido en la emboscada contra el dopaje. En este "todo vale" se soslaya la observación de uno de los pilares fundamentales que inspiran todo el sistema de lucha contra el dopaje tal es la protección de la salud del deportista. De esta forma, en ningún momento en la presentación de las Directrices Operativas del Pasaporte Biológico, los miembros de la AMA manifestaron interés alguno por dicha función tuitiva de la salud del atleta. Con todo, procede valorar sus pros y contras.

\footnotetext{
${ }^{21}$ Actualmente se encuentran vigentes las "Directricespara Pasaporte Biológico" cuya Versión es la 6.0, publicadas el 6 de septiembre de 2016. V. AMA, Athlete Biological Passport (ABP) Operating Guidelines. Version6.0, Montreal, Enero de 2017, disponible en: https://www.wadaama.org/sites/default/files/resources/files/guidelines_abp_v6_2017_jan_en_final.pdf

[Última consulta: 30 de octubre de 2017].

${ }^{22}$ V. el exhaustivo análisis de AMILIBIA PÉREZ, Guillermo, "El pasaporte biológico: luces y sombras. ¿Todo vale?", Iusport, 9 de abril de 2012, p. 11.
} 
Desde una valoración positiva, en primer lugar, se ha configurado como una alternativa contra las limitaciones a las que se enfrenta el sistema de detección directa ${ }^{23}$. De forma y manera que el sistema de controles actual sirve para detectar sustancias prohibidas o sus metabolitos o marcadores en las muestras tomadas al deportista. Si bien esta opción no está exenta de limitaciones. En primer lugar, la continua evolución biotecnológica hace que los sistemas de detección tengan que ir siempre un paso por detrás, haciendo muy dificultosa la fase de prevención, ya que el método consiste en perseguir las sustancias y métodos prohibidos, más todos aquellos que cumplen los criterios del artículo 4.3.1 del CMA. Asimismo, la dificultad a la hora de distinguir sustancias endógenas y exógenas se hace cada vez mayor, habida cuenta la creación de sustancias de similar estructura molecular a las originadas por el propio cuerpo con el fin de pasar desapercibidas en los controles. Por otra parte, el período de tiempo durante el cual los efectos de las sustancias son perceptibles por medio de biomarcadores (detección indirecta) es mucho mayor que el período de tiempo de permanencia de dichas sustancias en el cuerpo (detección directa). Sin obviar que la práctica o consumo de métodos o sustancias prohibidas de forma intermitente y en pequeñas dosis dificulta la detección de las sustancias, pero las variaciones en los biomarcadores sí son detectables.

En segundo término, la detección indirecta supone no tener que descubrir nuevos métodos de detección para cada nueva sustancia como única medida para luchar contra el dopaje. En este sentido, el uso del Pasaporte Biológico puede servir de instrumento, insistimos, complementario, para localizar sospechosos de llevar a cabo conductas prohibidas y así realizar sobre ellos controles programados.

No podemos dejar de hacer constar los inconvenientes que implica esta herramienta, tales como el coste tan elevado que supone su implementación. De esta forma, el Pasaporte Biológico, en comparación con el sistema actual, requiere un mucho mayor trámite burocrático, teniendo que realizar traslados de las pruebas desde los laboratorios en los cuales se realizan los análisis al Laboratorio de Lausana, en Suiza, y de allí, a la Comisión de Expertos.

Por otra parte, hemos de ser conscientes de que el fundamento del Pasaporte Biológico descansa en la especialidad e individualidad de la fisiología de cada uno. Por ello, los factores para ser aplicados con total garantía, deberían ser tenidos en cuenta en función de su afectación a cada deportista y no como factor general. Por lo tanto, no es extemporáneo preguntarse hasta qué punto se sabe cómo afectan los factores, por ejemplo, entrenar a una determinada altura o la raza, en el organismo de cada deportista.

\footnotetext{
${ }^{23}$ En este sentido, el pasaporte biológico no introduce una nueva prohibición, simplemente se trata de otro método de detección del dopaje. Como se declara repetidamente en los dictámenes del CAS, esta es la única manera de beneficiarnos de los avances tecnológicos con el fin de detectar violaciones de reglas antidopaje que no podrían ser detectados debido a los límites de los métodos anteriores. Cfr. MAVROMATI, Despina, "The Athlete's Biological Passport (ABP) Program. Legal issues arising out of the application of the ABP in the light of the Case Law of the Court of Arbitration for Sport (CAS)", CAS Bulletin/Bulletin TAS, 2011, pp. 35-43.
} 
Igualmente, cabe advertir que las anomalías en los valores de los perfiles del deportista representan únicamente una sospecha o indicio ${ }^{24}$ de dopaje sin necesidad de encontrar sustancia alguna en su cuerpo. En otros términos, el modelo de Pasaporte Biológico sólo es capaz de señalar la probabilidad ${ }^{25}$ de dopaje. Estaríamos, de este modo, ante un sistema indiciario que no es capaz de fijar con total certeza violación alguna, lo que supone una expansión de la responsabilidad objetiva más allá de los hechos que originan dicha responsabilidad. Este probabilismo no puede aceptarse en el contexto del sistema antidopaje en el que si es tan represivo como reza su regulación, ha de haber coherencia en los métodos de detección del mismo, los cuales han de ser igualmente rigurosos, habida cuenta en caso contrario se pone en peligro a los deportistas.

Al hilo de lo anterior, apuntar como inconveniente de este sistema la situación de indefensión que se genera en el deportista, que si con el sistema de detección directa ya es complicado para él, demostrar que no ha ingerido la sustancia prohibida de otra forma de la que él alega (probatio diabólica), si es que la sustancia en cuestión ha sido encontrada en su organismo, todavía resulta tarea más compleja defenderse explicando por qué sus niveles son anormales, sin haberse encontrado sustancia alguna.

De tal manera se puede entender que la doctrina ${ }^{26}$ afirme que la declaración de "no apto", y procedente suspensión, es una medida precipitada, injusta y que vulnera los derechos del deportista. En caso de que sus valores fuesen anómalos, éste podría ser declarado "no apto" para tomar parte en una competición, siendo suspendido durante un período de tiempo, sin saber o demostrarse que sea culpable, sufriendo el mismo daño (privación de competir) que si hubiese violado la normativa antidopaje. Con estos condicionantes, podemos decir que la prejudicialidad es más que notoria.

Sin duda, la cuestión más sangrante —especialmente para un jurista- que genera este sistema, es la vulneración de la presunción de inocencia ${ }^{27}$ (amén de una evidente presunción

\footnotetext{
${ }^{24}$ PALOMAR OLMEDA se muestra muy crítico respecto de un sistema que califica como "indiciario, basado en una serie de parámetros de anormalidad, cuyos fundamentos científicos están sujetos a una enorme cantidad de defectos metodológicos y de análisis, pero que tienen la virtualidad de 'arrojar' un indicio de duda aun sobre aquel queha pasado controles en el mismo periodo (incluidos los fuera de competición) y ha dado `no positivo"”. Cfr. PAlomar Olmeda, Alberto / Belda InIESTA, Cristóbal / LóPEZ-Collazo, Eduardo, "La necesidad de abordar el control del dopaje desde fundamentos diferentes: algunos puntos para una reflexión sobre bases diferentes", Revista Aranzadi de Derecho de Deporte y Entretenimiento, Núm. 44, 2014, pp. 21-49 pássim.

${ }^{25}$ SEOANE OSA refleja de forma contundente la postura del jurista subrayando que "a los juristas nos resulta aberrante una condena (cualquier tipo de sanción) basada en una posibilidad o probabilidad. Es decir, una condena basada en una estadística". Y considera un fracaso, no en sí el sistema, sino "el amparo en bases científicas que no alcanzan el rigor y exactitud exigidos por el derecho sancionador". Cfr. SEOANE OSA, Juan José, “Falsos positivos?”, Revista Aranzadi de Derecho de Deporte y Entretenimiento, Núm. 30, 2010, pp. 239-246.

${ }^{26}$ De nuevo AMILIBIA PÉREZ, Guillermo, “El pasaporte biológico: luces y sombras. ¿Todo vale?”, op. cit., p. 11. ${ }^{27}$ La doctrina aboga por el incremento de la transparencia en favor de la protección de los derechos de los atletas acusados de dopaje. V. KORNBECK, Jacob, "Private regulation and public trust: why increased transparency could strengthen the fight against doping”, Deutsche Zeitschrift für Sportmedizin, Núm. 5, Vol. 66, 2015, pp. 123-126 y KAYSER,Bengt E., "On the presumption of guilt without proof and intentionality and other consequences of current anti-doping policy", Doping and anti-doping policy in sport. Ethical, legal and social perspectives, MCNAMEE, Mike / MøLLER,Verner (Eds.), Routledge, Nueva York, 2011, pp. 84-99 y
} 
de culpabilidad) incluso sin haber "objeto" de incumplimiento (la presencia de una sustancia prohibida o de sus metabolitos o marcadores en la muestra de un deportista, o el uso de métodos prohibidos) o cuando los análisis arrojan resultados erróneos, habida cuenta el riesgo de los llamados "falsos positivos" o "falsos negativos" 28 está latente. En definitiva, parece que se justifica la violación de los derechos del deportista haciendo referencia a la noción de justicia deportiva "juego justo".

\section{Implicaciones para la intimidad de los sujetos}

Como hemos venido adelantando, no hay duda que el efecto inesperado - y no bien recibido por el jurista-, que ha generado la política antidopaje ha sido el de la potencial afección a los estándares de los derechos fundamentales. Como ejemplos más palpables destacan: la obligación de localización en materia de dopaje y la obligación de presencia $^{29}$ en un determinado lugar cada día del año para ser eventualmente sometido a controles fuera de competición.

La Agencia Española para la protección de la Salud en el Deporte (AEPSAD) ha de velar en el ejercicio de sus funciones, para que las condiciones de realización de los controles de dopaje previstos en la presente Ley se realicen ajustándose al principio de mínima intervención y velando por la proporcionalidad respecto del descanso nocturno del deportista y la afección de los derechos y la intimidad de los deportistas. De ahí que se establezca la limitación de una franja horaria para la realización de los controles. No en vano, por una parte, el artículo 11 (apartado primero) introduce una novedad importante ${ }^{30}$, respecto de la normativa anterior, en cuanto al alcance y la forma de realización de los controles antidopaje en la medida que ha de realizarse procurando una adecuada conciliación de los derechos

CONNOLlY, Ryan, "Balancing the justices in anti-doping law: the need to ensure fair athletic competition through effective anti-doping programs vs. the protection of rights of accused athletes", Virginia Sports and Entertainment Law Journal, Núm. 2, Vol. 5, 2006, pp. 78-80.

${ }^{28}$ Sobre esta problemática v. ELBEA, Anne-Marie / OVERBYEA, Marie, "Urine doping controls: the athletes' perspective", International Journal of Sport Policy and Politics, Núm. 2, Vol. 6, 2014, pp. 227-240; SANCHISGomar, Fabián /Martínez-Bello, Vladimir E /GómeZ-CABrera, Mari Carmen / Viña Jose, "Current limitations of the Athlete's Biological Passport use in sports", Clinical Chemistry and Laboratory Medicine, Núm. 9, Vol. 49, 2011, pp. 1413-1415.

29 Algunos autores se plantean la cuestión de los controles antidopaje como un supuesto de intromisión en el derecho a la intimidad de los deportistas desde el punto de vista de la capacidad obligacional de un tercero, ajeno a la relación deportista-federación, basada únicamente en que una de las partes de la relación (la federación) se ha integrado en una organización (la todopoderosa AMA) que tiene normas propias y cambiantes y que se integran por "asunción-remisión" en la relación jurídica del deportista sin que éste tenga más noticia que la mera constancia de la alianza entre la organización federativa y el ente instrumental. El resultado es que los deportistas, que no son miembros, ni socios, ni asociados, ni licenciados por la AMA, se ven obligados al cumplimiento de una serie de obligaciones que inciden en su libertad e intimidad sólo porque el que expide sus licencias pertenece a un "club" que impone reglas adicionales. En este punto resulta verdaderamente difícil de entender y de aceptar que obligaciones como la de la presencia de los deportistas en un lugar determinado durante todos los días del año sea una obligación proporcionada y admisible y que encuentre en el hecho voluntario de tener una licencia deportiva su justificación y cobertura. Cfr. PALOMAR OLMEDA, Alberto / PÉREZ GONZÁLEZ, Carmen, "La Libertad individual y la intimidad como límites necesarios a la actuación pública y privada en la actividad deportiva", Revista Aranzadi de Derecho de Deporte y Entretenimiento, Núm. 26, 2009, pp. 177-199.

${ }^{30}$ De la que se hace eco Fernández DE CASAdEVAnTe MAYORdOMO, Pablo, "Derecho a la intimidad y dopaje”, Revista Aranzadi de Derecho de Deporte y Entretenimiento, Núm. 43, 2014, pp. 90-91. 
fundamentales de los deportistas y de las necesidades materiales de la AEPSAD, particularmente, en lo que se refiere a la realización de controles fuera de competición; y por otra parte, el apartado tercero del artículo 15 establece que el desarrollo de los controles deberá realizarse con pleno respeto a los derechos fundamentales de los deportistas tal es el caso del derecho a la intimidad.

Antes de valorar la afección que supone, el control antidopaje, al derecho a la intimidad del deportista, conviene matizar unas cuestiones en torno a este derecho fundamental. Así, el derecho a la intimidad es recogido por primera vez en un texto constitucional español en 1978, sosteniendo el artículo 18.1 de nuestra Carta Magna que: "Se garantiza el derecho al honor, a la intimidad personal y familiar y a la propia imagen" 31 . La redacción de este precepto, donde se mencionan de forma conjunta estos tres conceptos ("honor", "intimidad" y "propia imagen") planteó dudas acerca de la configuración del derecho a la intimidad como un derecho único ${ }^{32}$. No obstante, hoy en día de forma mayoritaria ${ }^{33}$ se afirma la plena autonomía del derecho a la intimidad personal.

De otro lado, es posible afirmar que el derecho a la intimidad como derecho subjetivo de la personalidad fue concebido originariamente como un derecho de defensa que se manifestaba en la posibilidad de negar a terceros el conocimiento de las propias experiencias personales. Se identificaba con una suerte de derecho a "ser dejado en paz". Su ámbito de aplicación correspondía exclusivamente a la esfera de los datos "íntimos", es decir, a la información confidencial que el sujeto quiere ocultar a la curiosidad ajena. Lo íntimo se opone a lo público y se relaciona con la soledad o con lo restringido y lo reservado; en definitiva, con aquel núcleo de relaciones que el titular del derecho selecciona sin dar acceso a nadie más que a quien él y sólo él permita. Es importante subrayar que el concepto de intimidad presenta, por tanto, un contenido más acotado que el término "privacidad", que se identifica con la figura anglosajona denominada privacy y que viene referida a datos o informaciones no íntimos pero que el individuo desea que sólo sean conocidos por determinadas personas, queriendo sustraer su conocimiento a núcleos más amplios de la sociedad. En el ámbito objeto de nuestro estudio, reviste un papel protagonista el derecho a la intimidad en cuanto recae sobre los datos relativos a la salud de las personas. La denominada intimidad sanitaria se ha convertido de ese modo en una de las más señeras manifestaciones del derecho a la intimidad $^{34}$. Su creciente importancia se acompasa a la modernización del Estado social y

\footnotetext{
${ }^{31}$ Desarrolla ampliamente los derechos contemplados en el artículo 18.1 CE, SUÁREZ RUBIO, Soledad Mª, Constitución y Privacidad Sanitaria, Ed. Tirant lo Blanch, Valencia, 2015, pp. 58-84.

${ }^{32}$ Así, en el riguroso trabajo de FARIÑAS MATONI, el autor defiende que el derecho a la intimidad es único en cuanto a su concepción, pero múltiple y relativo en sus manifestaciones. FARIÑAS MATONI, Luis $\mathrm{M}^{\mathrm{a}}, \mathrm{El}$ derecho a la intimidad, Trivium, Madrid, 1983, p. 327.

${ }^{33}$ Resume la posición doctrinal predominante ESCRIBANO TORTAJADA: “(...) a pesar de haberse planteado un cierto debate sobre si el honor, la intimidad y la propia imagen son tres derechos diferenciados, es decir, autónomos, o por el contrario estamos ante un único derecho, en la actualidad, está plenamente aceptada la primera tesis, es decir, que nos encontramos ante tres derechos distintos y autónomos". Cfr. ESCRIBANO TORTAJADA, Patricia, "Algunas cuestiones sobre la problemática jurídica del derecho a la intimidad, al honor y a la propia imagen en internet y en las redes sociales", Los derechos a la intimidad y a la privacidad en el siglo XXI, FAYOS GARDÓ, Antonio (Coord.), Ed. Dykinson, Madrid, 2015, p. 63.

${ }^{34}$ SOLA RECHE, Esteban, "Derecho a la intimidad", Enciclopedia de Bioderecho y Bioética, Tomo I, ROMEO CASABOna, Carlos María, (Dir.), Ed. Cátedra Interuniversitaria de Derecho y Genoma Humano - Comares, Bilbao-Granada, 2011, p. 565.
} 
democrático con el reconocimiento del derecho a la salud de todos sus ciudadanos, y la consiguiente aplicación de importantes recursos públicos para hacerlo efectivo. Y se extiende tanto a la sanidad pública como a la privada, obligando a quienes en ellas participan con el deber de secreto profesional sobre las informaciones accesibles en el desempeño de las funciones correspondientes.

Llegados a este punto nos preguntamos en este contexto del deber de localización permanente y sus implicaciones para la intimidad de los sujetos si justifica su obligatoriedad el elemento de la protección de la salud individual y la salud pública; siempre sin olvidar que podemos hablar de tratamientos inocuos que desvirtúen esta tesis de protección de la salud como justificadora de la política antidopaje.

Con estos antecedentes podemos afirmar que lalucha contra el dopaje en el terreno deportivo está fundándose - y cada vez con mayor intensidad y conflictividad—, en la realización a los deportistas por parte de las organizaciones antidopaje de controles antidoping especialmente fuera de competición, siendo imperante en este sentido poder localizar al deportista. Bajo esta premisa, algunas organizaciones están exigiendo, por ende, la localización permanente de estos atletas. Ahora bien, nos plantearnos en este punto, si puede justificarse la obligación de localización de los deportistas y, por lo tanto, la intromisión en su intimidad para proteger un asunto que ha centrado nuestro trabajo, esto es, la salud. De este modo, valoraremos la cuestión desde el prisma de la salud individual y de salud pública.

Así las cosas, se nos antoja fundamental partir del Convenio para la Protección de los Derechos Humanos y la Dignidad del Ser Humano con respecto a las aplicaciones de la Biología y la Medicina (Convenio relativo a los Derechos Humanos y la Biomedicina), hecho en Oviedo el 4 de abril de $1997^{35}$, el cual detalla en su artículo 10 que "Toda persona tendrá derecho a que se respete su vida privada cuando se trate de informaciones relativas a su salud".Así, exige que todas las acciones se desarrollen con pleno respeto por los derechos fundamentales de las personas y, entre ellos, el respeto por la intimidad. Sin olvidar una disposición básica de la que se nutre, cual es, el Convenio Europeo de Derechos Humanos que en su artículo 8 establece el derecho al "respeto a la vida privada y familiar, domicilio y la correspondencia"36. Desde esta perspectiva, los datos relativos a las características genéticas de los sujetos, así como a su situación médica y sanitaria pertenecen, sin que haya atisbo de duda, a la esfera de la más estricta $\operatorname{privacidad}^{37} \mathrm{y}$, por ende, intimidad de las personas físicas, resultando indudable que la motivación que tenga por objeto tanto su captación, intento de conocimiento o su difusión puede provocar una intromisión ilegítima

\footnotetext{
35 Establece en su artículo 1 que "Las Partes en el presente Convenio protegerán al ser humano en su dignidad y su identidad y garantizarán a toda persona, sin discriminación alguna, el respeto a su integridad y a sus demás derechos y libertades fundamentales con respecto a las aplicaciones de la Biología y la Medicina".

${ }^{36}$ Con base a esta normativa cierto sector doctrinal considera que la política de los "whereabouts" parece suponer una violación a los derechos de los deportistas de élite contemplados en dicho Convenio. Cfr. MACGREGOR, Oskar / GRIFFITH, Richard / RUGGIU, Daniele / MCNAMEE, Mike, "Anti-doping, purported rights to privacy and WADA's whereabouts requirements: a legal analysis”,Fair Play. Revista de Filosofía, Ética y Derecho del Deporte, Núm. 2, Vol. 1, 2013, pp. 12-38.

${ }^{37}$ Es tratado in extenso en la monografía de NICOLÁs JiMÉNEZ, Pilar, La protección jurídica de los datos genéticos de carácter personal, Ed. Cátedra Interuniversitaria de Derecho y Genoma Humano - Comares, Bilbao-Granada, 2006.
} 
en la intimidad ${ }^{38}$, razón por la cual el entramado normativo en materia sanitaria -en coherencia y coordinación con dicha exigencia-, establece el carácter secreto de las historias clínicas e integra su contenido dentro del secreto profesional del personal sanitario.

Enlazando con este aspecto del secreto profesional de los agentes o profesionales sanitarios, se nos plantea el dilema de si éstos, con ocasión del ejercicio de su profesión conocen datos relativos a la intimidad del deportista y en especial si detectan posibles conductas de dopaje, es decir, un resultado positivo de control antidopaje - que no ha sido descubierto por los Agentes de Control - tienen obligación de guardar secreto respecto de dichos datos o, por el contrario, tendrían justificada su difusión. Entendemos que la excepción a este deber de sigilo profesional se presenta en el contexto del proceso penal, pues la exención del deber de declarar prevista en la Ley de Enjuiciamiento Criminal $^{39}$ no alcanza a los profesionales de la sanidad que, por tanto, estarán obligados a declarar sobre datos relativos a la intimidad del deportista de los que tengan conocimiento a través del ejercicio de su profesión. En otros términos, la difusión de los datos pudiera estar justificada en la medida en que puede derivar de tal difusión un comportamiento ilícito, que en la actualidad —con la LO 7/2006 se amplió el entramado sancionatorio administrativo al ámbito criminal aunque no al propio deportista (por el momento) - implica responsabilidad penal, y estar ante una circunstancia de interés general por su incidencia no sólo en la salud ${ }^{40}$ de las personas sino en la educación en valores de la sociedad y de la práctica del deporte ${ }^{41}$.

Retomando la cuestión de la justificación de dicha política, en primer lugar, con respecto a la salud individual de los deportistas, hemos de matizar que si bien la protección de la salud está regulada en el artículo 43 de la Carta Magna —y, por lo tanto, no está considerada como un derecho fundamental-, atendiendo al decisivo papel de la salud en relación con la protección de la persona y su dignidad, el TC ha vinculado la salud con otros derechos, como la integridad física para, de facto, dotarla de rango de derecho fundamental ${ }^{42}$. A

\footnotetext{
${ }^{38}$ De La IGLESIA Prados, Eduardo, Derecho Privado y deporte. Relaciones jurídico-personales, Ed. Reus, Madrid, 2014, pp. 436-437.

${ }^{39}$ En efecto, la obligación de denuncia viene consagrada con carácter general en los arts. 262 y 263 LECr, que si bien dispensan de la misma a determinados sujetos (en concreto a los abogados, procuradores, eclesiásticos y ministros de cultos disidentes), no menciona a otros profesionales, en concreto a los médicos, de modo que conforme a una interpretación estrictamente literal habría de concluirse afirmando que no están exentos del deber de denunciar. Cfr. Gómez Rivero, Carmen, "Secreto profesional (jurídico)", Enciclopedia de Bioderecho y Bioética, Tomo II, Romeo CASABOnA, Carlos María, (Dir.), Ed. Cátedra Interuniversitaria de Derecho y Genoma Humano - Comares, Bilbao-Granada, 2011, p. 1508. Ver también RoMEO CASABONA, Carlos María, "La protección penal del secreto profesional y laboralen el Derecho español", Estudios penales en recuerdo del Profesor Ruiz Antón,

OCtavio de Toledo y Ubieto, EmilioOctavio / Gurdiel SIERRA, Manuel / CORTÉs Bechiarelli,Emilio (Coords.), Ed. Tirant Lo Blanch, Valencia, 2003, pp. 959-990.

40 Cfr. Romeo Casabona, Carlos María,"La intimidad y losdatos de carácter personal como derechos fundamentales ycomo bienes jurídicospenalmenteprotegidos", Datospersonales.org: La Revista de la Agencia de Protección de Datos de la Comunidad de Madrid, Núm. 2, 2003, pp. 1-13.

${ }^{41}$ Así lo entiende también DE LA IGLESIA Prados, Eduardo, Derecho Privado y deporte. Relaciones jurídicopersonales, op. cit., pp. 437-438.

${ }^{42}$ La sentencia del TC 35/1996, de 11 de marzo, afirmó que "también el derecho a la salud, o mejor aún, a que no se dañe o perjudique la salud personal, queda comprendido en el derecho a la integridad personal". V. interesantes reflexiones sobre este asunto en RODRÍGUEZ GARCíA, José, "El deber de localización de los
} 
resultas de ello, nos encontramos en una situación de ponderación de dos derechos fundamentales ${ }^{43}$ : por un lado, el derecho a la intimidad y por otro, el derecho a la salud. Ahora bien, hemos de subrayar en este ámbito que se trata de derechos que tienen el mismo sujeto activo, esto es, el deportista sometido a la obligación de estar permanentemente localizado. Así, no parece atinada la ponderación entre dos derechos fundamentales que pertenecen a la misma persona. Y es que en este punto resulta fundamental el consentimiento de interesado, en la medida en que lo que se trata es de proteger su propia salud, la salud individual — posición distinta supone si es la salud pública lo que está en juego, como veremos más adelante - ya que, de no observar su voluntad, expresada mediante dicho consentimiento, nos situaríamos en una tendencia paternalista, superada ya en nuestros tiempos.

Redundando en esta idea, el TC en la sentencia 154/2002, de 18 de julio, afirmó que "cobra especial interés el hecho de que, al oponerse el menor a la injerencia ajena sobre su propio cuerpo, estaba ejercitando un derecho de autodeterminaciónque tiene por objeto el propio sustrato corporal — como distinto del derecho a la salud o a la vida — y que se traduce en el marco constitucional como un derecho fundamental a la integridad física (artículo $15 \mathrm{CE}$ )".

Por consiguiente y a tenor de la doctrina del $\mathrm{TC}^{44}$, hemos de concluir que para que pueda producirse la intromisión en los derechos fundamentales de los deportistas, derivada de la obligación de localización permanente, con el objeto de preservar la salud individual de éstos, su consentimiento resulta vital.

No obstante, se hace necesario destacar que con respecto a la voluntariedad del individuo están previstas, en la esfera sanitaria, determinadas excepciones derivadas de la irrenunciable protección de la salud pública. Este planteamiento se enlaza con el dopaje puesto que éste adquiere - como parece desprenderse de la Exposición de Motivos de la LO 7/2006- la categoría de problema de salud pública, porque afecta "tanto a los deportistas profesionales como a los practicantes habituales u ocasionales de alguna actividad deportiva", así "como a la práctica deportiva de base que, con carácter recreativo y saludable, desarrollan en nuestro país millones de personas". En nuestro país el legislador se decantaba por preservar la salud pública en el ámbito de la lucha contra el dopaje, tipificando determinadas acciones con la introducción del originario artículo 361 bis — cuyo contenido, sobra a estas alturas, insistir, ha resultado idéntico al vigente 362 quinquies - en el Código Penal, a través de la pretérita LO 7/2006, dentro precisamente de los delitos contra la salud pública. Este delito persigue la protección de la salud de cualquier persona que practique un deporte, bien en práctica competitiva o bien de forma recreacional, de tal manera que "cualquier restricción de los

deportistas y su derecho a la intimidad: especial referencia al consentimiento", Revista Aranzadi de Derecho de Deporte y Entretenimiento, Núm. 31, 2011, pp. 181-248.

${ }^{43}$ Ya nos pronunciábamos sobre ello en ATIENZA MACÍAS, Elena, "La protección de los derechos fundamentales del deportista en la lucha contra el dopaje. Una visión desde el ordenamiento jurídico español", Boletín Mexicano de Derecho Comparado, nueva serie, año XLVII, Núm. 140, Mayo-Agosto de 2014, pp. 417448.

${ }^{44}$ Así, la jurisprudencia del TC, por todas su sentencia 120/1990, de 27 de junio, al referirse a la afección en la integridad física y moral del individuo en relación con la salud de las personas, ha dicho que la integridad física y moral "protege la inviolabilidad de la persona, no sólo contra ataques dirigidos a lesionar su cuerpo o espíritu, sino también contra toda clase de intervención en esos bienes que carezca del consentimiento de su titular". 
sujetos pasivos de la infracción hubiera resultado incoherente, ya que la actividad deportiva debe ponerse al alcance de todas las personas, respetando las aspiraciones y capacidades de cada uno y con toda la diversidad de prácticas competitivas o de ocio, organizadas o individuales" $"$.

Una vez sentada la constitucionalidad del bien "salud pública", no podemos dejar de ignorar la colisión existente entre ese bien y el derecho fundamental de los deportistas a su intimidad, que reclama una solución de forma inexcusable. La ponderación entre el derecho a la intimidad de los deportistas sometidos a la obligación de localización permanente y la preservación de la salud pública ha de iniciarse valorando la relevancia de la intervención en el derecho fundamental y la del fin perseguido, siendo en este caso la salvaguardia de la salud pública.

Respecto a este punto, cierta doctrina ${ }^{46}$ entiende que la incidencia en el derecho a la intimidad de los deportistas ${ }^{47}$, como consecuencia de la obligación de localización permanente, es de una magnitud tal, que implica que debe considerarse violado el contenido esencial del derecho; y frente a ello, la salud pública, si bien es incuestionable como objetivo relevante, parece que no se puede considerar muy mejorada con esta obligación de localización, por una serie de razones.

Por un lado, la protección de la salud pública implica o trasciende a la protección de cualquier persona que practique un deporte bien de forma competitiva o recreacional. De tal forma que la salud pública se vería mejorada si la lucha contra el dopaje alcanzase a todos los practicantes de la actividad deportiva, sea de manera habitual u ocasional. Vemos que en la realidad esto no sucede así puesto que los controles de dopaje se están efectuando, salvo algunas excepciones, solo a los deportistas profesionales de élite o de alto nivel; y de estos deportistas un número realmente reducido es sancionado por dopaje.

Pero por otro lado, la obligación de facilitar todos los datos precisos que permitan la localización de los deportistas no conlleva que se pongan en marcha medidas concretas y serias para mejorar la salud pública, en este caso reflejadas en controles antidopaje, sino tan sólo significa que esos controles podrían llegar a realizarse, pero no que efectivamente se estén realizando.

\footnotetext{
${ }^{45}$ V. CORTÉS BeChiARELli, Emilio, El delito de dopaje, Ed. Tirant lo Blanch, Valencia, 2007, p. 65.

${ }^{46}$ V. más ampliamente RoDRíGUEZ GARCíA, José, "El deber de localización de los deportistas y su derecho a la intimidad: especial referencia al consentimiento", op. cit. pp. 181-248.

${ }^{47}$ Se han realizado distintos estudios que se centran en transmitir la perspectiva o postura que los propios deportistas de élite muestran respecto al sistema de los "whereabouts" llegando al resultado de que dicho sistema actual necesita mejorarse con el fin de aumentar la propia satisfacción de los atletas. Asimismo, los resultados de este tipo de estudios indican que la mayoría de los deportistas no están dispuestos a aceptar una mayor violación de su privacidad de lo que la normativa actual ya implica. Entre ellos puede consultarse el de VALKENBURG, Diane / DE Hon, Olivier / VAN Hilvoorde, Ivo, "Doping control, providing whereabouts and the importance of privacy for elite athletes", International Journal of DrugPolicy, Núm. 2, Vol. 25, Marzo 2014, pp. 212-218 y BourdonA, Fanny / ScHOCHB, Lucie / BroERsC, Barbara / KAYSERB, Bengt, "French speaking athletes' experience and perception regarding the whereabouts reportingsystem and therapeutic use exemptions", Performance Enhancement \& Health, Núms. 3-4, Vol. 3, Septiembre-Diciembre 2014, pp. 153158.
} 
Concluimos acorde con esta doctrina que la incidencia positiva en la salud pública que supone la obligación de localización de los deportistas es muy escasa. Especialmente de la ponderación de ambos valores en juego se extrae que el sacrificio del derecho a la intimidad de los deportistas es muy alto y, frente a ello, el beneficio que adquiere la salud pública derivado de tal sacrificio es muy bajo ${ }^{48}$. Y en el caso concreto de la figura del Pasaporte Biológico, como ya avanzábamos, no se prevé tan siquiera e incluso podemos decir que se soslaya esta función tuitiva de la salud del deportista ya que, en ningún momento en la presentación de las Directrices Operativas del Pasaporte Biológico, los miembros de la AMA manifestaron interés alguno por la protección de la salud del atleta ${ }^{49}$. De tal manera que se contempla la posibilidad de la limitación de derechos en el caso de un interés legítimo que lo justifique y dicho interés legítimo parece que no existe en el caso del Pasaporte Biológico.

Por lo tanto, podríamos afirmar con prudencia que debe prevalecer, este caso y con las actuales condiciones, el derecho a la intimidad de los deportistas sobre la salud pública, por lo que la obligación que les es impuesta de facilitar a las organizaciones antidopaje los datos que permitan localización permanente no supera el juicio de proporcionalidad en sentido estricto $^{50}$.

Sobre este extremo se ha pronunciado un sector de la doctrina ${ }^{51}$, en particular MoLINA NAVARRETE, quiende forma muy contundente ha llegado a afirmar que "la legitimidad de eventuales controles fuera de competición y por sorpresa, por tanto en un ámbito

\footnotetext{
${ }^{48}$ V. de nuevo RodRíGuez GARCíA, José, "El deber de localización de los deportistas y su derecho a la intimidad: especial referencia al consentimiento",op. cit., pp. 181-248.

Desde otra perspectiva más cercana a la Filosofía del Deporte, TAMBURRINI se cuestiona la razón de mantener un procedimiento como el de la sistema del control antidopaje que resulta moralmente cuestionable y que no trae consigo beneficio fáctico alguno (textualmente lanza el interrogante siguiente: "Why keep a morally dubious procedure which renders no factual benefit whatsoever?"), en TAMBURRINI, Claudio, "WADA's antidoping policy and athletes' right to privacy", Fair Play. Revista de Filosofía, Ética y Derecho del Deporte, Núm. 2, Vol. 1, 2013, p. 95.

${ }^{49}$ V. AMILIBIA PÉREZ, Guillermo, "El pasaporte biológico: luces y sombras. ¿Todo vale?”, Iusport, 9 de abril de 2012, p. 11.-12.El autor trae, muy oportunamente, a colación famosos pronunciamientos que a estas alturas de nuestro trabajo de investigación ya nos son bien conocidos: el Caso Bosman C-415/93 (PAR. 104) y el Caso Bernard C-325/08 (par. 38 y ss) sobre la libre circulación de trabajadores. En lo que respecta al dopaje, este poder conferido al interés legítimo se encuentra reconocido en el párrafo 45 del Caso Meca-Medina C-519-04: "Así, aun suponiendo que una normativa antidopaje deba ser apreciada como una decisión de una asociación de empresas que limita la libertad de acción de las personas a las que se destina, no puede constituir forzosamente una restricción de la competencia incompatible con el mercado común, en el sentido del artículo $81 \mathrm{CE}$, puesto que está justificada por un objetivo legítimo. En efecto, tal limitación es inherente a la organización y al buen funcionamiento de la competición deportiva y busca precisamente garantizar una rivalidad sana entre los atletas".

${ }^{50}$ Así lo exponíamos en ATIENZA MACÍAS, Elena, "Control antidoping y derecho a la intimidad", Globalización y Derecho: desafíos y tendencias, GómEZ ISA, Felipe / ENCISO SANTOCILDES, Marta / EMALDI CIRIÓN, Aitziber (Eds.), Publicaciones de la Universidad de Deusto, Bilbao, 2013, pp. 433-447. Y de ello se hace eco DE LA IGLESIA PRADOS, Eduardo, Derecho Privado y deporte. Relaciones jurídico-personales, op. cit., pp. 441 y $445-$ 460.
}

\footnotetext{
${ }^{51}$ V. Molina NAVARRETE, Cristóbal, Nadal contra los "vampiros" de la AMA: la lucha por el derecho a la intimidad en la relación deportiva profesional,Ed. Aranzadi, Cizur Menor, 2010, pp. 69-76y en esta línea se manifiestaViÑUElAS ZAHÍnOS, Ma Teresa, "Análisis jurídico de los controles sorpresa de dopaje", Dopaje, fraude y abuso en el deporte, BOSCH CAPDEVILA, Esteve / FRANQUET SUGRAÑES, María Teresa (Coords.), Ed. Bosch, Barcelona, 2007, pp. 72-74.
} 
extralaboral, debe siempre conciliarse con el respeto del derecho fundamental a una vida privada controlada por el deportista ${ }^{52}$ en una parte suficiente para que el derecho sea reconocido en nuestra cultura". Desde esta perspectiva, siempre es necesario mantener, aun aceptando limitaciones adicionales por el marco organizativo, institucional y contractual específicos del deporte y la fuerza del imperativo del juego limpio, el juicio de proporcionalidad. Con todo, si bien es loable la lucha contra el dopaje, como postura encaminada, en particular, a la protección de la salud de los deportistas, las medidas que se prevean para erradicar estas conductas antideportivas deberían superar el juicio de proporcionalidad, mediante sistemas que entronquen con la legalidad y que en sí mismos o en sus modos o formas de ejecución no posibiliten actuaciones vulneradoras de los derechos fundamentales de los deportistas ${ }^{53}$, en especial y por lo aquí tratado, del derecho a la intimidad entendido con amplitud.

En línea semejante, se pronuncian PUNZÓN MORALEDA y SÁNCHEZ RodRíGUEZ, cuando afirman que "no es posible aceptar el lema de que el fin justifica todos los medios. Nuestro Estado es un Estado de Derecho, debe actuar como tal y siempre debe dar la imagen de que actúa de esta forma. Frente a la polémica de los controles de la AMA estamos a favor de la realización de controles antidopaje pero, no por menos, debemos afirmar que estos controles deben ser respetuosos con los derechos fundamentales con los que cuentan los deportistas, así como con la protección de sus datos personales, la inviolabilidad de su domicilio y el respeto a su vida privada pues toda persona tiene derecho al menos a mantener un nicho vital donde mantener su ego guarecido de las asechanzas externas. Si no se ponen límites precisos a esta intromisión habría que preguntarnos el por qué no incorporar a los deportistas seleccionados un microchip en su $\operatorname{piel}^{54}(. .$.$) ".$

Frente a esta línea argumental, no falta doctrina ${ }^{55}$ que estima que la actividad legisladora española en materia de localización de los deportistas ha ido en paralelo a las exigencias que se han ido realizando, sobre todo, desde la AMA, si bien debe señalarse que en modo alguno ha cedido al afán de dicho organismo por anteponer la localización de los deportistas a

\footnotetext{
${ }^{52}$ Resulta muy ilustrativa la comparación del sistema ADAMS, en el seno del circuito ciclista, con un "Gran Hermano" omnipresente que todo lo ve y controla: V. en la doctrina la obra colectiva Kontrolsport: Big Brother blandt atleterogtilskuere, CHRISTIANSEN, Ask Vest (Ed.), University of Southern Denmark Studies in History and Social Sciences, Vol. 385, Odense, Dinamarca, 2009 y en la prensa: "ADAMS, el nuevo `Gran Hermano" del ciclismo", Diario Vasco, 23 de enero de 2008, disponible en: http://www.diariovasco.com/20080123/deportes/adams-nuevo-gran-hermano-20080123.html [Última consulta: 30 de octubre de 2017].

${ }^{53}$ V. PUNZÓN MORALEDA, Jesús / SÁNCHEZ RoDRÍGUEZ, Francisco, "Una situación ambivalente del derecho de deporte: la lucha contra el dopaje y la defensa del derecho de intimidad", Revista Aranzadi de Derecho de Deporte y Entretenimiento,Núm. 26, 2009, pp. 141-158.

${ }^{54} \mathrm{Se}$ pueden consultar las reflexiones desde la perspectiva del Derecho Penal en ARMAZA ARMAZA, Emilio José, "El control telemático del delincuente imputable peligroso en Derecho Penal", La adaptación del Derecho Penal al desarrollo social y tecnológico, ROMEO CASABONA, Carlos María / SÁNCHEZ LÁZARO, Fernando Guanarteme (Eds.), ArmaZA ARMAZA, Emilio José (Coord.), Ed. Comares, Granada, 2010, pp. 429 y ss. Consúltese asimismo DE LA MATA BARRANCO, Norberto J. / BARINAS UBIÑAS, Désirée, "La privacidad en el diseño y el diseño de la privacidad, también desde el Derecho Penal”, Eguzkilore: Cuaderno del Instituto Vasco de Criminología, Núm. 28, 2014, pp. 253-274.

${ }^{55}$ Cfr. FernándeZ DE CASADEVAnTE MAYORDOMO, Pablo, "Derecho a la intimidad y dopaje", op. cit., pp. 9091.
} 
cualquier otra consideración. En este sentido, y en relación con la información que el deportista debe aportar, entendemos que la proporcionalidad entre los medios y los objetivos de la normativa es un hecho, sobre todo tras la rectificación obrada en relación con la injusta e injustificada obligación de localización permanente prevista en la anulada Resolución de la Presidencia del Consejo Superior de Deportes o CSD, de 30 abril de 2009 (a la que se añade la también anulada Resolución de 4 de febrero de 2013, igualmente, de la Presidencia del CSD, por la que se aprueba el formulario de localización de los deportistas) ${ }^{56}$. No obstante,

${ }^{56}$ La sentencia de la Audiencia Nacional (Sala de lo Contencioso Administrativo, Sección Sexta) de 24 de junio de 2014 (Rec. 138/2013), declara que el Anexo II de la resolución impugnada, al exigir un deber de localización permanente y no habitual, como prevé el artículo 5.3 de la fenecida LO 7/2006, ("localización habitual" es el término que se recoge en el artículo 11.3 de la vigente LO 3/2013) contiene un exceso al extralimitarse del contenido legal, e igualmente reglamentario (al infringir asimismo el artículo 45.1 del mencionado RD 641/2009), debiéndose en consecuencia declarar la nulidad del contenido del formulario referido al deber de localización ocasional. Desde esta perspectiva advierte la sentencia que se trata de una medida desproporcionada y contraria al derecho a la intimidad, y no amparada legalmente. Considera que si bien se confirma la legitimidad de los controles contra el dopaje, especialmente en los períodos de fuera de competición, en los que los tratamientos de dopaje pueden, efectivamente, ser más frecuentes por las mayores dificultades de control, no obstante, una medida que somete al deportista a un control permanente durante todas las jornadas y horas del año, excediendo así de lo que pueda considerarse como "habitual o frecuente" es una medida desproporcionada y contraria al derecho a la intimidad, y no amparada legalmente, aun admitiendo el deber de sujeción especial que tiene el deportista como titular de una licencia federativa, en tanto podría llegar a equipararse a medidas de carácter penal de localización permanente que sólo pueden imponerse como consecuencia de la comisión de un delito. Con todo, acorde a dicho pronunciamiento, tal localización permanente supondría una injerencia que no respeta el contenido esencial del derecho a la intimidad. Un comentario que incluye el texto íntegro de la sentencia de la Audiencia Nacional en REDACCIÓN IUSPORT, "La Audiencia Nacional anula el formulario de localización de los deportistas", Iusport, 2 de julio de 2014, disponible en: http://iusport.com/not/2432/la-audiencia-nacional-anula-el-formulario-de-localizacion-de-losdeportistas/ [Última consulta: 30 de octubre de 2017]. Sobre ella podemos encontrar sendos comentarios: Cfr. PÉREZ TRIVIÑO, José Luis, "Controles antidopaje y garantías fundamentales de los deportistas", Revista Aranzadi de Derecho de Deporte y Entretenimiento, Núm. 45, 2014, pp. 95-110; DE MiguEL PAJUELO, Francisco, "Vulneración del derecho a la intimidad al exigir una localización permanente de los deportistas para el control del dopaje. Comentario a la sentencia de la audiencia nacional de 24 de junio de 2014", Revista Aranzadi de Derecho de Deporte y Entretenimiento, Núm. 45, 2014, pp. 299-316 y LAS HERAS ROMERO, Carlos, "La localización permanente de los deportistas como supuesto no contemplado en el ordenamiento español. Comentario a la Sentencia de la Audiencia Nacional de 24 de junio de 2014", Revista Aranzadi de Derecho de Deporte y Entretenimiento, Núm. 44, 2014, pp. 179-190.En efecto, el Profesor PALOMAR OLMEDA hace unos años ya abogaba por "recomponer la figura y decir claramente que las iniciativas contra el dopaje son tan importantes que sólo son legítimas si se realizan en el marco de la legalidad", a propósito del eterno debate sobre los problemas que derivan de la forma en que los ordenamientos nacionales vienen estableciendo el esquema de respeto a la libertad, la intimidad y los derechos de las personas. Cfr. PALOMAR OLMEDA, Alberto, "De nuevo sobre la represión del dopaje o la necesidad de recomponer la figura", Revista Andaluza de Derecho del Deporte, Núm. 8, 2010, pp. 43-50 y 56-57.

Como colofón, el Tribunal Supremo, en sentencia de 28 de julio de 2016 -y confirmando la sentencia de la Audiencia Nacional de 24 de junio de 2014-, anulaba definitivamente el Anexo II de la Resolución de 4 de febrero de 2013 de la Presidencia del CSD, por la que se aprueba el formulario de localización de los deportistas (incluidos en el Plan Individualizado de Controles), al considerar que la aplicación del citado Anexo implicaría someter al deportista a una "localización permanente" que afecta al derecho a su intimidad y excede el contenido de la Ley Orgánica 3/2013, de 20 de junio, de protección de la salud del deportista y lucha contra el dopaje en la actividad deportiva. V. ATIENZA MACÍAS, Elena "Sobre la colisión que desencadena el control antidopaje con el derecho a la intimidad del deportista. ¿El Alto Tribunal pone fin al debate "localización habitual versus localización permanente"? Comentario a la Sentencia del Tribunal Supremo, Sala de lo Contencioso-Administrativo, Sección Cuarta, de 28 de julio de 2016", Revista Aranzadi de Derecho del Deporte y Entretenimiento, Núm. 54, Enero-Marzo 2017, pp. 319-335. 
dicho equilibrio queda desvirtuado si tenemos en cuenta que la AMA impone en su normativa un deber de localización mucho más intenso que en el caso español, lo cual implica su aceptación por parte del deportista que quiera participar en las competiciones sujetas a la regulación de dicha Agencia. En concreto, y pese a que, como ya se ha visto, la Ley 3/2013 habla de una localización habitual en los términos reglamentariamente previstos, por ejemplo, los artículos 11.1.3; 11.1 .4 y 11.3 del International Standard for Testing de 2012 exigen una información muchísimo más detallada, traspasando el ámbito de protección otorgado por la legislación española.

\section{Referencias bibliográficas}

Álvarez VIEJo, Julia Amada, "El caso de Marta Domínguez: el pasaporte biológico", Revista Aranzadi de Derecho de Deporte y Entretenimiento, Núm. 42, 2014.

AmiliBIA PÉREZ, Guillermo, "El pasaporte biológico: luces y sombras. ¿Todo vale?", Iusport, 9 de abril de 2012.

Armaza ArmazA, Emilio José, "El control telemático del delincuente imputable peligroso en Derecho Penal", La adaptación del Derecho Penal al desarrollo social y tecnológico, Romeo CASABOna, Carlos María / SÁnchez LÁzAro, Fernando Guanarteme (Eds.), ArmaZA ArmaZA, Emilio José (Coord.), Ed. Comares, Granada, 2010.

ATIENZA MACÍAS, Elena "Sobre la colisión que desencadena el control antidopaje con el derecho a la intimidad del deportista. ¿El Alto Tribunal pone fin al debate "localización habitual versus localización permanente"? Comentario a la Sentencia del Tribunal Supremo, Sala de lo Contencioso-Administrativo, Sección Cuarta, de 28 de julio de 2016", Revista Aranzadi de Derecho del Deporte y Entretenimiento, Núm. 54, Enero-Marzo 2017.

Atienza Macías, Elena/ Armaza Armaza, Emilio José, El dopaje en el Derecho Deportivo actual: análisis y revisión bibliográfica, Ed. Reus, Madrid, 2016.

ATIENZA MACÍAS, Elena, "Control antidoping y derecho a la intimidad", Globalización y Derecho: desafíos y tendencias, GómEZ IsA, Felipe / ENCISO SANTOCILDES, Marta / EMALDI CIRIÓn, Aitziber (Eds.), Publicaciones de la Universidad de Deusto, Bilbao, 2013.

Bourdona, Fanny / Schochb, Lucie / Broersc, Barbara / KAYSERB, Bengt, "French speaking athletes' experience and perception regarding the whereabouts reporting system and therapeutic use exemptions", Performance Enhancement \& Health, Núms. 3-4, Vol. 3, Septiembre-Diciembre 2014.

CONNOLLY, Ryan, "Balancing the justices in anti-doping law: the need to ensure fair athletic competition through effective anti-doping programs vs. the protection of rights of accused athletes", Virginia Sports and Entertainment Law Journal, Núm. 2, Vol. 5, 2006.

Cortés Bechiarelli, Emilio, El delito de dopaje, Ed. Tirant lo Blanch, Valencia, 2007. 
De La Iglesia Prados, Eduardo, Derecho Privado y deporte. Relaciones jurídicopersonales, Ed. Reus, Madrid, 2014.

De La Mata Barranco, Norberto J. / Barinas Ubiñas, Désirée, "La privacidad en el diseño y el diseño de la privacidad, también desde el Derecho Penal”, Eguzkilore: Cuaderno del Instituto Vasco de Criminología, Núm. 28, 2014.

De Miguel Pajuelo, Francisco, "Vulneración del derecho a la intimidad al exigir una localización permanente de los deportistas para el control del dopaje. Comentario a la sentencia de la audiencia nacional de 24 de junio de 2014", Revista Aranzadi de Derecho de Deporte y Entretenimiento, Núm. 45, 2014.

DVORAK, Jiri et ál., "Time for change: a roadmap to guide the implementation of the World Anti-Doping Code 2015”, British Journal of Sports Medicine, Núm. 10, Vol. 48, 2014.

ElbeA, Anne-Marie / OverbyeA, Marie, "Urine doping controls: the athletes' perspective", International Journal of Sport Policy and Politics, Núm. 2, Vol. 6, 2014.

Escribano TORTAJADA, Patricia, "Algunas cuestiones sobre la problemática jurídica del derecho a la intimidad, al honor y a la propia imagen en internet y en las redes sociales", Los derechos a la intimidad y a la privacidad en el siglo XXI, FAYOS GARDÓ, Antonio (Coord.), Ed. Dykinson, Madrid, 2015.

FARIÑAS MATONI, Luis Ma , El derecho a la intimidad, Trivium, Madrid, 1983.

Fernández de CASAdeVAnte MAyordomo, Pablo, "Derecho a la intimidad y dopaje", Revista Aranzadi de Derecho de Deporte y Entretenimiento, Núm. 43, 2014. 2010 .

GiLbert,Susan, "The Biological Passport”, Hastings Center Report, Núm. 2, Vol. 40,

GLEAVES, John, "What to do once they're caught", Cycling - Philosophy for Everyone: A Philosophical Tour de Force, IlundÁIn-AgurRuZA, Jesús / Austin, Michael W. (Eds.), Wiley-Blackwell, Malden, 2010.

Gómez Rivero, Carmen, "Secreto profesional (jurídico)", Enciclopedia de Bioderecho y Bioética, Tomo II, Romeo Casabona, Carlos María, (Dir.), Ed. Cátedra Interuniversitaria de Derecho y Genoma Humano - Comares, Bilbao-Granada, 2011.

HARDIE, Martin, "Lance Armstrong”,Drugs and Sport, MøLler,Verner / WADDINGTON, Ivan / Hoberman, John M. (Eds.), Ed. Routledge, Nueva York, 2015.

HUNTER, Mark, "Would-be cheats face barrage of tests by army of antidoping scientists at London Olympics", British Medical Journal, Núm. 7823, Vol. 343, 2011. 
KAYSER,Bengt E., "On the presumption of guilt without proof and intentionality and other consequences of current anti-doping policy", Doping and anti-doping policy in sport. Ethical, legal and social perspectives, MCNAMEE, Mike / MøLLER,Verner (Eds.), Routledge, Nueva York, 2011.

KORNBECK, Jacob, "Private regulation and public trust: why increased transparency could strengthen the fight against doping", Deutsche Zeitschrift für Sportmedizin, Núm. 5, Vol. 66, 2015 .

LAS HERAS ROMERO, Carlos, "La localización permanente de los deportistas como supuesto no contemplado en el ordenamiento español. Comentario a la Sentencia de la Audiencia Nacional de 24 de junio de 2014", Revista Aranzadi de Derecho de Deporte y Entretenimiento, Núm. 44, 2014.

MacGregor, Oskar / Griffith, Richard / RugGiu, Daniele / MCNAMEe, Mike, "Antidoping, purported rights to privacy and WADA's whereabouts requirements: a legal analysis",Fair Play. Revista de Filosofía, Ética y Derecho del Deporte, Núm. 2, Vol. 1, 2013.

Mavromati, Despina, “The Athlete's Biological Passport (ABP) Program. Legal issues arising out of the application of the ABP in the light of the Case Law of the Court of Arbitration for Sport (CAS)", CAS Bulletin/Bulletin TAS, 2011.

Mavromatia, Despina, "Indirect detection methods for doping from a legal perspective: the case of the Athlete Biological Passport", International Journal of Sport Policy and Politics, Núm. 2, Vol. 6, 2014.

Molina NAVARRETE, Cristóbal, Nadal contra los "vampiros" de la AMA: la lucha por el derecho a la intimidad en la relación deportiva profesional, Ed. Aranzadi, Cizur Menor, 2010.

NiCOLÁs JimÉNeZ, Pilar, La protección jurídica de los datos genéticos de carácter personal, Ed. Cátedra Interuniversitaria de Derecho y Genoma Humano - Comares, BilbaoGranada, 2006.

Palomar Olmeda, Alberto / BeldaIniesta, Cristóbal / LóPez-Collazo, Eduardo, "La necesidad de abordar el control del dopaje desde fundamentos diferentes: algunos puntos para una reflexión sobre bases diferentes", Revista Aranzadi de Derecho de Deporte y Entretenimiento, Núm. 44, 2014.

Palomar Olmeda, Alberto / Pérez GonzÁlez, Carmen, "La Libertad individual y la intimidad como límites necesarios a la actuación pública y privada en la actividad deportiva", Revista Aranzadi de Derecho de Deporte y Entretenimiento, Núm. 26, 2009.

Palomar Olmeda, Alberto, "De nuevo sobre la represión del dopaje o la necesidad de recomponer la figura", Revista Andaluza de Derecho del Deporte, Núm. 8, 2010. 

DEPORTIVO: EL PASAPORTE BIOLÓGICO

PATRICK, Kirsten, "Passport to clean competition", British Medical Journal, Núm. 7858, Vol. 344, 2012, p. 20 y HAILEY, Nicholas, "A false start in the race against doping in sport: concerns with cycling's biological passport”, Duke Law Journal, Núm. 2, Vol. 61, 2011.

PÉREZ Triviño, José Luis, "Controles antidopaje y garantías fundamentales de los deportistas", Revista Aranzadi de Derecho de Deporte y Entretenimiento, Núm. 45, 2014.

PunZÓn MoraledA, Jesús / SÁnCHEZ RodRíGueZ, Francisco, "Una situación ambivalente del derecho de deporte: la lucha contra el dopaje y la defensa del derecho de intimidad", Revista Aranzadi de Derecho de Deporte y Entretenimiento,Núm. 26, 2009.

REDACCIÓN IUSPORT, "La Audiencia Nacional anula el formulario de localización de los deportistas", Iusport, 2 de julio de 2014.

RoDRÍGUEZ GARCíA, José, "El deber de localización de los deportistas y su derecho a la intimidad: especial referencia al consentimiento", Revista Aranzadi de Derecho de Deporte y Entretenimiento, Núm. 31, 2011.

RODRÍGUEZ GARCíA, José, "El pasaporte hematológico como nuevo elemento de prueba en la lucha contra el dopaje", Dopaje deportivo y Código Mundial Antidopaje, DE VICENTE Martínez, Rosario (Dir.), Millán Garrido, Antonio (Coord.), Ed. Reus, Madrid, 2014.

Romeo Casabona, Carlos María, "La intimidad y los datos de carácter personal como derechos fundamentales y como bienes jurídicos penalmente protegidos", Datospersonales.org: La Revista de la Agencia de Protección de Datos de la Comunidad de Madrid, Núm. 2, 2003.

Romeo Casabona, Carlos María, "La protección penal del secreto profesional y laboral en el Derecho español", Estudios penales en recuerdo del Profesor Ruiz Antón, OCTAVIO DE Toledo y Ubieto, Emilio Octavio / Gurdiel Sierra, Manuel / Cortés Bechiarelli, Emilio (Coords.), Ed. Tirant Lo Blanch, Valencia, 2003.

SANCHIS-GOMAR, Fabián /MARTÍnEZ-Bello, Vladimir E /GóMEZ-CABrerA, Mari Carmen / Viña Jose, "Current limitations of the Athlete's Biological Passport use in sports", Clinical Chemistry and Laboratory Medicine, Núm. 9, Vol. 49, 2011.

SeOAne Osa, Juan José, “¿Falsos positivos?”, Revista Aranzadi de Derecho de Deporte y Entretenimiento, Núm. 30, 2010.

Sola Reche, Esteban, "Derecho a la intimidad", Enciclopedia de Bioderecho y Bioética, Tomo I, Romeo CASABONA, Carlos María, (Dir.), Ed. Cátedra Interuniversitaria de Derecho y Genoma Humano - Comares, Bilbao-Granada, 2011.

SuÁRez Rubio, Soledad Ma, Constitución y Privacidad Sanitaria, Ed. Tirant lo Blanch, Valencia, 2015. 
TAMBURRINI, Claudio, "WADA's anti-doping policy and athletes' righttoprivacy", Fair Play. Revista de Filosofía, Ética y Derecho del Deporte, Núm. 2, Vol. 1, 2013.

TeIXeIRA SilveIRA, Viviane / Rigo, Luiz Carlos, "O programa passaporte biológico: considerações sobre o governo dos atletas”, Movimento, Núm. 2, Vol. 21, Abril-Junio 2015.

Valkenburg, Diane / De Hon, Olivier / VAn Hilvoorde, Ivo, "Doping control, providing whereabouts and the importance of privacy for elite athletes", International Journal of Drug Policy, Núm. 2, Vol. 25, Marzo 2014

VERnEC,Alan R., "The Athlete Biological Passport: an integral element of innovative strategies in antidoping”, British Journal of Sports Medicine, Núm. 10, Vol. 48, 2014.

ViÑUELAS ZaHÍNOS, M ${ }^{\mathrm{a}}$ Teresa, "Análisis jurídico de los controles sorpresa de dopaje", Dopaje, fraude y abuso en el deporte, Bosch CAPDEVILA, Esteve / FRANQUET SUGRAÑES, María Teresa (Coords.), Ed. Bosch, Barcelona, 2007.

VIRET, Marjolaine, “Athlete Biological Passport: a paradigm shift?”,Evidence in antidoping at the intersection of Science \& Law, Springer - ASSER International Sports Law Series, Berlín, 2015.

Zorzoli, Mario / PIPE, Andrew Lawrence / GARnIER, Pierre-Yves / DvorAK, Jiri, "Practical experience with the implementation of an athlete's biological profile in athletics, cycling, football and swimming", British Journal of Sports Medicine, Núm. 10, Vol. 48, 2014.

ZORZOLI,Mario / RoSSI, Francesca, "Implementation of the biological passport: the experience of the International Cycling Union", Drug Testing and Analysis, Special Issue: 28th Cologne Workshop: Advances in Sports Drug Testing, Núms. 11-12, Vol. 2, 2010.

ZORZOLI, Mario, "Biological passport parameters", Journal of Human Sport and Exercise, Núm. Extra 1, Vol. 6, 2011.

ZORZOLI, Mario, "The Athlete Biological Passport from the perspective of an anti-doping organization”, Clinical Chemistry and Laboratory Medicine, Núm. 9, Vol. 49, 2011. 